\title{
Impacts of marine invaders on biodiversity depend on trophic position and functional similarity
}

\author{
Mads S. Thomsen ${ }^{1,2, *}$, James E. Byers ${ }^{3}$, David R. Schiel ${ }^{1}$, John F. Bruno ${ }^{4}$, \\ Julian D. Olden ${ }^{5}$, Thomas Wernberg ${ }^{2,6}$, Brian R. Silliman ${ }^{7}$ \\ ${ }^{1}$ Marine Ecology Research Group, School of Biological Sciences, University of Canterbury, Private Bag 4800, Christchurch, \\ New Zealand \\ ${ }^{2}$ UWA Oceans Institute and School of Plant Biology, University of Western Australia, Hackett Drive, Crawley, \\ Western Australia 6009, Australia \\ ${ }^{3}$ Odum School of Ecology, University of Georgia, Athens, Georgia 30602, USA \\ ${ }^{4}$ Department of Biology, University of North Carolina, Chapel Hill, North Carolina 27599, USA \\ ${ }^{5}$ School of Aquatic \& Fishery Sciences, University of Washington, Seattle, Washington 98195, USA \\ ${ }^{6}$ Australian Institute of Marine Science, 39 Fairway, Crawley, Western Australia 6009, Australia \\ ${ }^{7}$ Division of Marine Science and Conservation, Nicholas School of the Environment, Duke University, Durham, \\ North Carolina 27708, USA
}

\begin{abstract}
Impacts of marine invaders on local biodiversity have not been analyzed across invasive species and invaded habitats. We conducted a meta-analysis of 56 field experiments published in 29 papers that examined the effects of marine invaders on local species richness, diversity, and/or evenness. We show that invaders, across studies, typically have negative effects on biodiversity within a trophic level but positive effects on biodiversity of higher trophic levels. For example, both plants and sessile filter-feeders had positive effects on richness and diversity of mobile consumers. The contrasting negative and positive effects on similar versus higher trophic levels are potentially manifested through community-wide antagonism (competition and consumption) versus facilitation (habitat and food provisioning) interactions, respectively. These relationships extended to functional interactions, as sessile invaders had negative effects on the biodiversity of sessile communities (intra-functional interactions) but positive effects on the biodiversity of mobile communities (inter-functional interactions). Our analyses highlight the importance of pairing attributes of the invader and the impacted organisms to obtain simple predictions of how the diversity of entire communities may respond to species invasions on local scales. We also note that our analysis did not require information on co-evolutionary history but that such data, coupled with long-term large-scale mensurative data, are needed to gain a comprehensive predictive insight into invasion impact.
\end{abstract}

KEY WORDS: Invasive species · Impact analysis · Diversity $\cdot$ Richness $\cdot$ Evenness $\cdot$ Meta-analysis · Attribute matching

Resale or republication not permitted without written consent of the publisher

\section{INTRODUCTION}

Impacts of species invasions have traditionally been studied on individuals and populations of native taxa, while overlooking how entire communities and biodiversity metrics (e.g. taxonomic richness, diversity, and evenness) have been affected (Parker et al. 1999, Byers et al. 2002, Cucherousset \& Olden 2011). This lack of emphasis on community-wide effects is reflected in recent reviews of marine invasion impacts (e.g. Byers 2009, Crooks 2009, Grosholz \& Ruiz 2009, Rilov 2009b, Thomsen et al. 2011b) where only 2 
case-studies were reviewed, highlighting that invasive marsh plants can reduce richness of native plants (reviewed by Byers 2009) and infauna (reviewed by Grosholz \& Ruiz 2009). Still, a growing number of primary studies have aimed to quantify impacts on biodiversity (e.g. Ross et al. 2007, Gribben et al. 2009, Bulleri et al. 2010, Thomsen 2010), subsequently inspiring researchers to test broad questions about drivers of invasion impacts across invasive taxa and habitats using meta-analytical frameworks (i.e. calculating direction and magnitude of standardized effect sizes; Gaertner et al. 2009, Thomsen et al. 2009, Powell et al. 2011, Vilà et al. 2011). These meta-analyses show that invasive plants, across studies, have negative effects on local plant biodiversity but either negative (Vilà et al. 2011) or possible positive (Thomsen et al. 2009) effects on animal biodiversity. These conclusions build primarily on data extracted from terrestrial surveys (with the exception of Thomsen et al. 2009).

However, there are potential problems associated with reviewing effects on biodiversity from surveys. First, these data cannot separate causes and effects (Sol et al. 2008) and may therefore confound invasion impact (where the invader is the independent variable) with invasion success (where the invader is the dependent variable). Second, it is difficult to identify all relevant primary studies (because invasion impact from survey data blend into invasion success studies), thereby potentially introducing study selection bias (Englund et al. 1999). Third, surveys are often conducted on larger and longer scales (Sol et al. 2008, Powell et al. 2011) and therefore investigate different ecological mechanisms, sometimes producing contradictory results compared to experiments (Fridley et al. 2007, Powell et al. 2011). By contrast, manipulative field experiments do not confound success and impact and are conducted on relatively similar spatio-temporal scales. Thus, although existing meta-analyses have concluded that invasive plants generally have negative impacts on local plant biodiversity, these studies have not focused on (1) how biodiversity of local animals is affected or (2) how invasive animals impact local biodiversity. Furthermore, primary studies from (3) field experiments and (4) marine ecosystems have been severely underrepresented. Here we target these 4 research gaps, analyzing marine field experiments to test whether invaders occupying different trophic positions have different effects on the biodiversity of communities composed of different trophic positions. More specifically, we tested whether biodiversity effects within a trophic level are more negative than those on a higher trophic level (Fig. 1), because we expect com- petition to be strong on controphic communities (Gaertner et al. 2009, Thomsen et al. 2009, Powell et al. 2011, Vilà et al. 2011), whereas provision of food and habitats could facilitate higher trophic communities (Rodriguez 2006, Thomsen et al. 2010). We refer to this model as a relative trophic position hypothesis, because we examined whether knowledge about the broad trophic position of both the invader and the impacted community together can explain, and thereby predict, a significant proportion of the large variability often detected between invasion impact studies (Strayer et al. 2006, Thomsen et al. 2011b).

We note that the trophic position hypothesis is related to a broader distinctiveness hypothesis which also emphasizes that the attributes of the invader and the native species should be paired to predict impact (Ricciardi 2003, Thomsen et al. 2011a). The distinctiveness hypothesis suggests that invasion impact is large if invasive and local species are functionally and/or taxonomically different from each other (Diamond \& Case 1986, Ricciardi 2003, Ricciardi \& Atkinson 2004). This theory does not explicitly specify an expected effect size direction (being 'larger' can involve being more negative or more positive). The distinctiveness model has been supported in a meta-

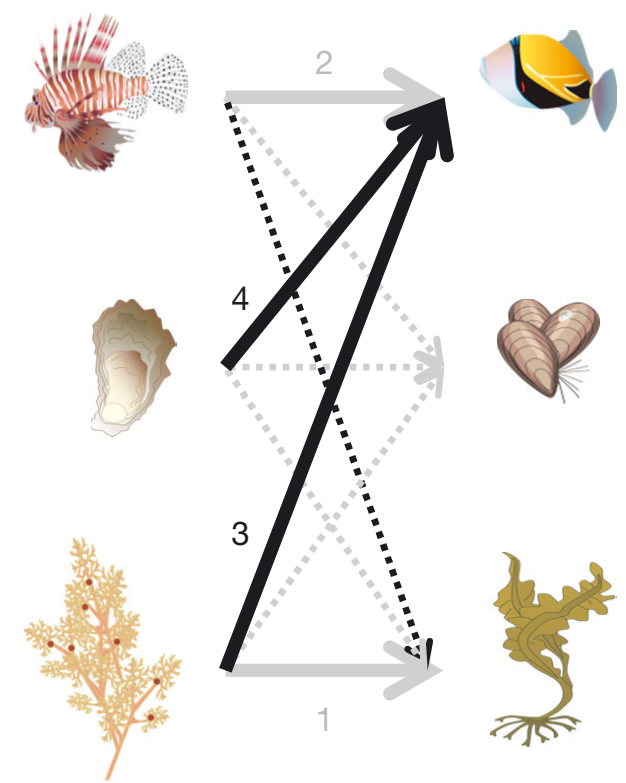

Fig. 1. Conceptual model of the relative trophic position hypothesis. Sessile plants, sessile filter-feeders, and mobile consumers have negative impacts (grey solid arrows, Subhypotheses 1 and 2) on controphic local species through competition and consumption but positive impacts (black solid arrows, Sub-hypotheses 3 and 4) on higher trophic levels through provision of food and habitat. Dashed lines correspond to trophic position sub-hypotheses that could not be tested due to a paucity of primary studies. Images and symbols used in the figure courtesy of the Integration and Application Network (ian.umces.edu/symbols/) 
analysis that tested effects of taxonomic relatedness (Ricciardi \& Atkinson 2004). However, we are not aware of any studies that have tested whether pairing functional attributes can predict invasion impact on the biodiversity of local communities. We therefore repeated the trophic position test with a functional position test, using 'mobility' as a simple functional attribute that has often been analyzed in marine invasion studies (Sellheim et al. 2010, Thomsen et al. 2010) and that is related to trophic position (e.g. plants and most filter-feeders are sessile). In this test we compared effect sizes between mobile and sessile invaders on biodiversity of local sessile and mobile communities, expecting that effect sizes are numerically larger across than within the same functional position (Diamond \& Case 1986, Ricciardi 2003, Ricciardi \& Atkinson 2004).

\section{MATERIALS AND METHODS}

We located peer-reviewed studies, in which the abundance of marine invaders was controlled in replicated field experiments and which compared invaded treatments to non-invaded control plots using invader-addition or -removal manipulations (Thomsen et al. 2009), by searching ISI databases, including the Web of Science, Current Contents, and Google Scholar, using various combinations of the terms 'experiment*', 'invader*', 'alien*', 'exotic*', 'nonindigenous*', 'non-native*', 'impact*', 'effect*', 'affect*', 'community*', 'diversity ${ }^{* \prime}$, 'richness ${ }^{* \prime}$, 'assemblage structure ${ }^{* \prime}$, and 'marine*' in 'title' and 'abstract' sections. We also identified relevant experiments by back-tracking references in previous reviews and meta-analyses on marine invasion impacts (Bruno et al. 2005, Schaffelke \& Hewitt 2007, Williams 2007, Williams \& Smith 2007, Byers 2009, Crooks 2009, Grosholz \& Ruiz 2009, Rilov 2009a,b, Thomsen et al. 2009, 2011b). We read more than 700 abstracts and method sections and identified more than 100 relevant field experiments (see Thomsen et al. 2011a,b for preliminary data compilations). However, only 29 of these publications reported effects on biodiversity metrics, i.e. on richness, diversity, or evenness with mean values, sample sizes, and standard deviations (or other measures of data dispersion). For each of these papers, we classified manipulated invaders as plants, filter-feeders, or mobile consumers, where filter-feeders were treated as a separate intermediate trophic position that are plant-like in their low mobility and habitat provisioning but animal-like in terms of their heterotrophic diet (see Supplement 1 for de- tails at www.int-res.com/articles/suppl/m495p039_ supp.pdf). Unfortunately, we found too few studies to separate consumer effects into grazer, omnivore, and predator effects. To address the functional position hypothesis, plants and filter-feeders were merged as sessile invaders. Impacts on local communities are typically reported on coarse trophic or functional groups and could therefore only be classified as impacts on plant communities (e.g. Piazzi \& Ceccherelli 2006), animal communities (e.g. Albins \& Hixon 2008), mixed plant+animal communities (e.g. Griffen \& Byers 2009), sessile communities (e.g. Thomsen 2010), mobile communities (Sellheim et al. 2010), or mixed mobile+sessile communities (Hollebone \& Hay 2008, Thomsen 2010). We also extracted data about the experimental duration and plot sizes to examine whether effects on biodiversity were confounded by spatio-temporal co-variation in the experimental arena. We followed standard methods by only extracting the last data point from repeated-measures experiments (Salo et al. 2007, Vilà et al. 2011) and comparing controls to the highest invader density from multi-density experiments (Vilà et al. 2011), thereby avoiding strong within-experiment autocorrelation (Borenstein et al. 2009). We also followed standard methods by treating the same invasive species tested in multiple studies (e.g. Parker et al. 2006, Morales \& Traveset 2009) and by including orthogonal and nested experiments (e.g. Gurevitch et al. 2000, Parker et al. 2006) as 'independent subgroups within a study' (Borenstein et al. 2009) (more conservative approaches supported our findings, see Supplement 2 at www.int-res.com/articles/suppl/m495 p039_supp.pdf). A few studies reported impacts on multiple communities, e.g. on plant and animal communities (Gribben et al. 2009), which were treated here as independent observations (Kaplan et al. 2008, Vilà et al. 2011). If an experiment reported impacts on multiple diversity responses, these data were treated as non-independent 'multiple outcomes/comparisons within study' (Borenstein et al. 2009) and averaged into a single independent effect size per experiment. Effects sizes for each experiment were standardized by calculating Hedges' $d$ (see Eq. 1), a common metric in ecological meta-analyses (e.g. Salo et al. 2007, Kaplan et al. 2008, Gaertner et al. 2009, Morales \& Traveset 2009, Oduor et al. 2010):

$$
d=\left[\left(X_{\text {invaded plot }}-X_{\text {control plots }}\right) / \mathrm{SD}_{\text {pooled }}\right] \times J
$$

where $X_{\text {invaded plot }}$ and $X_{\text {control plots }}$ represent the mean diversity metric reported from the invaded and noninvaded plots respectively, and $J$ is a correction factor for low sample sizes that approaches 1 for large sam- 
ples $(=1-\{3 /[4(\mathrm{~N} 1+\mathrm{N} 2)-9]\})$. Note that if invaders reduce biodiversity, $d$ is negative. Hedges' $d$ is unit free and ranges from $-\infty$ to $+\infty$ where numerical values of $0.2,0.5,0.8$, and 1 represent 'small,' 'medium,' 'large,' and 'very large' effects, respectively, corresponding to Pearson's correlation coefficient $r$ of 0.10 , $0.24,0.37$, and 0.45 (Rosenberg et al. 2000). We examined potential publication bias by correlating $d$ values with their corresponding sample sizes and variance and by calculating weighted Rosenthal's failsafe number (Vilà et al. 2011). Few studies reported effects on diversity and evenness, and these metrics were therefore pooled for the presented analysis.

We found few diversity/evenness data for the relative functional position analysis, and this test was therefore only conducted on richness responses. We analyzed the trophic and functional position hypotheses with unweighted random effect ANOVAs (Kaplan et al. 2008, Morales \& Traveset 2009; weighted and fixed models produced similar results, $M$. Thomsen unpubl.) and calculated cumulative effect sizes $\left(d_{\text {cumulative }}\right)$, sample heterogeneity $\left(Q_{\text {total }}\right)$, and $95 \%$ bias-corrected confidence limits (CLs). All statistical analyses were carried out in Metawin 2.1 (Rosenberg et al. 2000). A $d_{\text {cumulative }}$ value was interpreted to be significantly different from 0 or another $d_{\text {cumulative }}$ if the $95 \%$ CLs did not overlap 0 or each other, respectively (as in Kaplan et al. 2008, Morales \& Traveset 2009, Vilà et al. 2011).

\section{RESULTS}

Our meta-analysis examined impacts on biodiversity of 18 marine invasive species, including 6 plants, 7 sessile filter-feeders, and 5 mobile consumers.

\section{Trophic position: richness}

The overall heterogeneity of effect size was relatively small $\left(Q_{\text {total }}=83, \mathrm{df}=69, \mathrm{p}=0.12\right.$ where $Q$ approximates an asymptotic chi-squared distribution) indicating that individual effect sizes could share a common value. Importantly, $d_{\text {cumulative }}$ differed significantly among $\left(Q_{\text {between }}=19, \mathrm{p}\left(\chi^{2}\right)=0.002, \mathrm{df}=5\right)$, but not within $\left(Q_{\text {within }}=64, \mathrm{p}\left(\chi^{2}\right)=0.47, \mathrm{df}=64\right)$ the impact types examined. There was a near-significant overall negative effect of invaders on the taxonomic richness of local communities (Fig. 2A: 'All'). However, we found clear contrasting positive and negative effects when the attributes of invaders and local communities were separated according to their trophic position. Effects from invaders on native communities that occupy similar trophic positions (plants on plant communities, consumers on animal communities) were statistically similar and significantly more negative than where native communities included higher trophic levels than the invader (plants on ani-
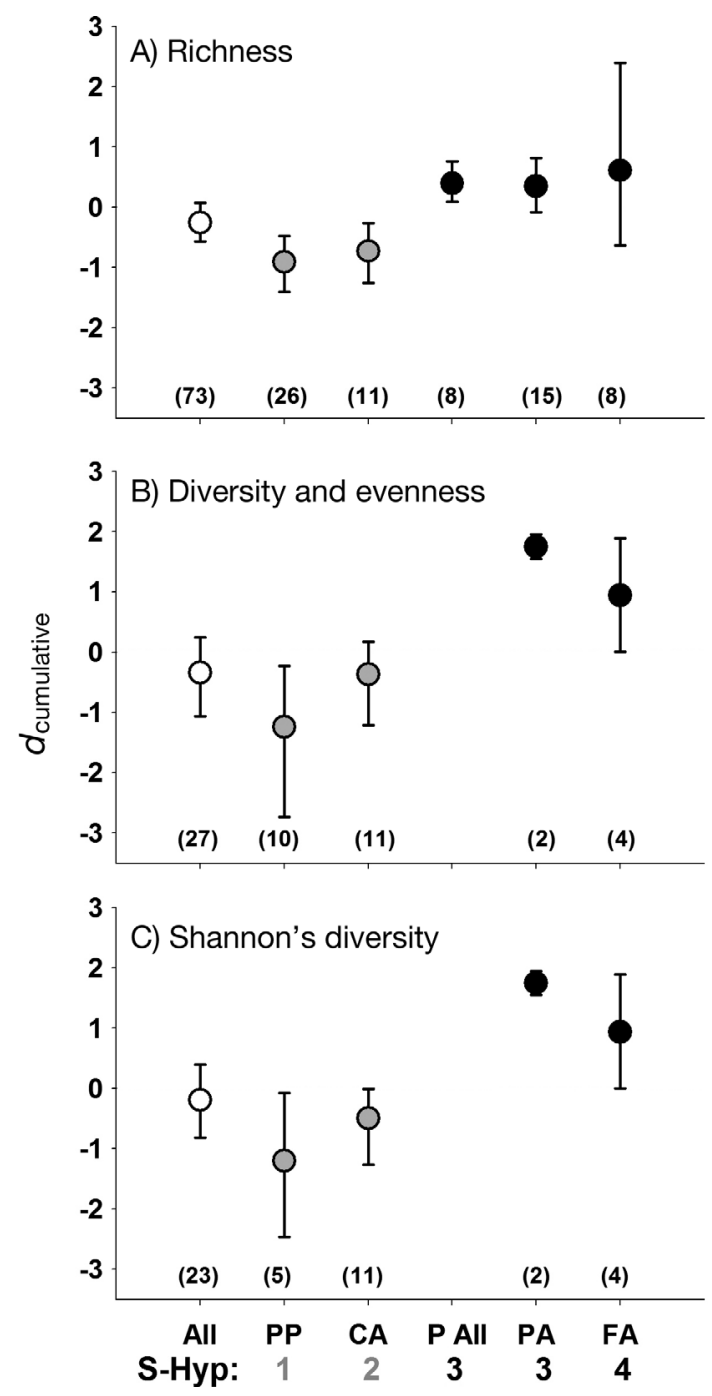

Fig. 2. Meta-analytical evaluation of the relative trophic position hypothesis (see Fig. 1 for conceptual model). Impacts of marine invaders were evaluated on (A) local taxonomic richness, (B) diversity and evenness combined, and (C) Shannon's diversity. Invaders (first letters) were divided into plants $(\mathrm{P})$, sessile filter-feeders $(\mathrm{F})$, and mobile consumers (C), and local communities (second letters) into plant- (P), animal- (A), and mixed plant+animal communities (All). Numbers in parentheses correspond to replicated experiments. S-Hyp: sub-hypothesis (see Fig. 1). $d_{\text {cumulative: cumu- }}$ lative effect size. Fill color corresponds to hypothesized dominating interaction, where grey $=$ competition and/or consumption, black = habitat formation and/or food provision. Empty circles correspond to mean effects pooled within and across trophic position and therefore do not have an expected interaction. Error bars are $95 \%$ confidence limits 
mal communities, plants on mixed plant+animal communities, filter-feeders on animal communities). More specifically, we found significant negative effects of invasive plants on plant communities, and invasive consumers on animal communities, but a significant positive effect of invasive plants on mixed plant+animal communities. We also found a large (but non-significant) effect of invasive plant and filter-feeders on animal communities. Certain trophic position combinations could not be evaluated statistically because of low sample sizes, e.g. impacts of invasive consumers on plant communities $\left(d_{\text {cumulative }}=\right.$ $0.03, \mathrm{n}=1$ ) and invasive consumers on plant+animal communities $\left(d_{\text {cumulative }}=0.05, \mathrm{n}=2\right)$.

\section{Trophic position: diversity+evenness combined}

The overall heterogeneity of effect sizes was small $\left(Q_{\text {total }}=32, \mathrm{df}=26, \mathrm{p}=0.19\right)$, again suggesting that effect sizes share a common value. Also, $d_{\text {cumulative }}$ again differed significantly among $\left(Q_{\text {between }}=9, \mathrm{p}\left(\chi^{2}\right)=\right.$ 0.029, $\mathrm{df}=3)$ but not within $\left(Q_{\text {within }}=23, \mathrm{p}\left(\chi^{2}\right)=0.46\right.$, $\mathrm{df}=23)$ the examined impacts. Although fewer trophic position combinations were available for analysis, our general hypothesis was supported; effects from invaders on native communities that occupy similar trophic positions (invasive plants on plant communities, invasive consumers on animal communities) were statistically similar and significantly more negative than when native communities included higher trophic levels than the invader (invasive filter-feeders on animal communities). Invasion impact averaged across trophic positions was not significantly different from 0 (Fig. 2B; 'All'). However, partitioning by trophic position showed a significant negative impact of invasive plants on plant communities and a near-significant negative impact of invasive consumers on animal communities but a significant positive impact of invasive filter-feeders on animal communities. Effects could not be evaluated for several trophic position combinations, including invasive plants on animal communities $\left(d_{\text {cumulative }}=1.76, \mathrm{n}=2\right)$ or invasive consumers on plant communities $\left(d_{\text {cumulative }}=0.41, \mathrm{n}=1\right)$.

\section{Trophic position: Shannon diversity}

The overall heterogeneity of effect sizes was relatively small $\left(Q_{\text {total }}=29, \mathrm{df}=21\right)$ and not significant $(\mathrm{p}=0.10) ; d_{\text {cumulative }}$ differed significantly among $\left(Q_{\text {between }}=11, \mathrm{p}\left(\chi^{2}\right)=0.009, \mathrm{df}=3\right)$ but not within $\left(Q_{\text {within }}=18, \mathrm{p}\left(\chi^{2}\right)=0.46, \mathrm{df}=18\right)$ impact types exam- ined. There was no overall effect of invaders on the taxonomic richness of local communities (Fig. 2C; 'All'), but we found contrasting positive and negative effects when the attributes of invaders and local communities were separated according to their trophic position. Effects from invaders on native communities that occupy similar trophic positions (plants on plant communities, consumers on animal communities) were statistically similar and significantly more negative than where native communities included higher trophic levels than the invader (plants on animal communities, filter-feeders on animal communities). More specifically, we found significant negative effects of invasive plants on plant communities, and invasive consumers on animal communities, but significant positive effect of invasive plants on animals and invasive filter-feeders on animal communities. Effects could not be evaluated statistically for some combinations of trophic positions due to low sample sizes or complete lack of primary data.

\section{Functional position: richness}

The overall heterogeneity of effect sizes was relatively small $\left(Q_{\text {total }}=85, \mathrm{df}=60\right)$ but significant $(p=0.02)$, suggesting that these effect sizes did not share a common value. Again, $d_{\text {cumulative }}$ differed significantly among $\left(Q_{\text {between }}=29, \mathrm{p}\left(\chi^{2}\right)<0.001\right.$, df $\left.=4\right)$, but not within $\left(Q_{\text {within }}=56, \mathrm{p}\left(\chi^{2}\right)=0.47\right.$, $\left.\mathrm{df}=56\right)$ treatments. We found no effect of invaders on the taxonomic richness of local communities when functional attributes were not paired (Fig. 3; 'All') but contrasting effects when the attributes were paired. Thus, effects of invaders on local communities that occupied similar functional positions were significantly negative but positive when occupying different positions. Effects of invaders on biodiversity of mixed communities containing both sessile and mobile organisms were not significantly different from 0 .

\section{DISCUSSION}

Marine invaders influence local communities in numerous ways (Crooks 2009, Grosholz \& Ruiz 2009), and their impacts are typically considered contextdependent varying with a complex mixture of invader attributes, as well as resource levels, abiotic conditions, and community structure of the invaded habitats (Strayer et al. 2006, Thomsen et al. 2011a, Ricciardi et al. 2013). This complexity is expected to be even more pronounced on aggregated community 


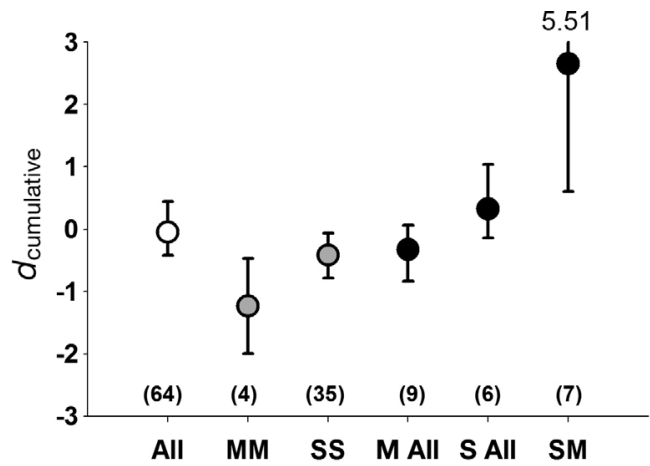

Fig. 3. Meta-analytical evaluation of the relative functional position hypothesis. Impacts of marine invaders were evaluated on local taxonomic richness. Invaders (first letters) were divided into sessile (S) and mobile (M) species, and local communities (second letters) into sessile (S), mobile (M), and mixed mobile+sessile communities (All). Numbers in parentheses correspond to replicated experiments. $d_{\text {cumulative: }}$ cumulative effect size. Fill color corresponds to hypothesized dominating interaction, where grey $=$ competition and/or consumption, black = habitat formation and/or food provision. Empty circle corresponds to mean effects pooled within and across trophic position and therefore does not have an expected interaction. Error bars are 95\% confidence limits

responses (e.g. richness, diversity, evenness) because inter-connected responses from tens to hundreds of ecologically different species could cancel out or exaggerate species-specific effects. It is, therefore, a challenge for invasion biology to identify simple rules that can explain part of this context variability. We found support for a simple trophic position hypothesis, i.e. invaders had negative effects on biodiversity within trophic levels but less negative or even positive effects on biodiversity at higher trophic levels. This result supports previous meta-analyses that have quantified negative impacts from plant invaders on local plant biodiversity (Gaertner et al. 2009, Thomsen et al. 2009, Powell et al. 2011, Vilà et al. 2011). We also found support for the meta-analysis of Thomsen et al. (2009), which found preliminary data to suggest that invasive plants may have positive impacts on animal biodiversity (evaluated from a few marine experiments). Still, the latter result contrasts with the analysis of Vilà et al. (2011), which found negative effects of invasive plants on animal diversity. This discrepancy could be because the latter study mainly reviewed terrestrial survey data, whereas we only included experimental data from marine ecosystems. Indeed, positive effects on neighborhood scales (the arena for trophic interactions and experimental research) may be relatively common in marine systems, where habitat modification by sessile species is a fundamental process to increase biodiversity (Wahl 1989, Bruno \& Bertness 2001, Thomsen et al. 2010).
We suggest that the negative effects seen within trophic levels most likely are driven by competition (as suggested more specifically for plant-plant interactions by Gaertner et al. 2009, Thomsen et al. 2009, Powell et al. 2011, Vilà et al. 2011) and, for animals, a combination of competition and consumption processes. We also suggest that positive effects on higher trophic levels (e.g. invasive plants on animals) could be driven by habitat-formation and food provision. These ecological interactions are also suggested in the reviewed primary studies, e.g. for plant-plant interactions (Viejo 1997, Piazzi et al. 2005), animalanimal interactions (Albins \& Hixon 2008), and plant-animal interactions (Thomsen et al. 2010). Impacted communities that included multiple trophic levels (e.g. mixed plant+animal communities) were positively affected, and the underlying facilitation mechanism could therefore again be habitat formation and modification (Gribben et al. 2009, Thomsen et al. 2010). We also found positive impacts of filterfeeders on animal biodiversity - a finding not described in previous meta-analyses. This result suggests that invasive filter-feeders, like plants, may facilitate local animal communities by providing habitat and food. These mechanisms have been demonstrated to be particularly strong for the invasive bryozoan Watersipora subtorquata (Sellheim et al. 2010). Note, however, that data variability was large, reflecting that only few primary studies existed and that invasive filter-feeders also compete with native sessile species for limited space (Blum et al. 2007)

We found contrasting effects on diversity metrics when the functional attributes of the invader and local communities were paired; effects of invaders with similar functions as the impacted community were negative, whereas effects of invaders with different functions were less negative or positive. This finding supports the distinctiveness hypothesis, because effect sizes depend on whatever invasive and local species are functionally or taxonomically different from each other or not (Diamond \& Case 1986, Ricciardi \& Atkinson 2004). However, our results also highlight that effect size 'direction' should be incorporated in the distinctiveness hypothesis to differentiate positive and negative species interactions. Our functional similarity test thereby builds on the previous meta-analysis that focused on negative effects only (Ricciardi \& Atkinson 2004). We also suggest that when functionality is equated with mobility (mobile vs. sessile), competition dominates within functional groupings (Viejo 1997, Piazzi et al. 2005), whereas habitat formation and food provisioning 
dominate across functional groupings (Sellheim et al. 2010, Thomsen et al. 2010).

Our analyses were likely limited by data variability, research bias, and low inference space, reflecting that the analysis is based on relatively few primary studies. However, data variability was not a major problem because we did find many significant effects to support our general hypotheses. Our analysis could also be limited by different types of autocorrelation between Hedges' $d$ values, but we found no correlations between effect sizes and plot sizes, experimental duration, and sample sizes (Supplement 2). Auto-correlation may also exist between studies quantifying effects on the same invasive species or under similar experimental conditions, but more conservative supplementary analyses gave similar results (Supplement 2). Finally, our results may be biased because significant results are easier to publish than non-significant results and because 'pet-species/interactions' are more fashionable to study than others (Rosenthal 1979, Borenstein et al. 2009). These types of bias are difficult to quantify, but by applying strict study inclusion criteria, we made our data compilation transparent (Supplement 1). It is likely that a standard research emphasis on studying a few high-impact invaders and on publishing large significant effects has inflated the effect sizes we report. However, we suggest that the above biases are less likely to affect effect size direction and that our conclusions are therefore relatively robust. Still, our conclusions should only cautiously be interpolated beyond the context of the reviewed studies (Supplement 1).

From an ecological perspective, it is important to discuss limitations associated with the few broad trophic/functional groupings analyzed. We had to focus on these groups out of necessity because diversity effects are only reported on broad types of communities and because only certain types of invasive species have been tested. The implication of analyzing coarse groupings is that many invasions may not follow the trophic/functional position rules. For example, some invasive plants and filter-feeders can, in contrast to our predictions, have positive effects on biodiversity within trophic groups, e.g. through habitat formation (Thomsen et al. 2010), and invasive plants may have both positive and negative effects on higher trophic levels depending on type and pathway of the dominant interactions, for example, through third- or fourth-order consumption cascades (Eastwood et al. 2007, Tronstad et al. 2010). We did not test how invaders affect biodiversity of lower trophic levels because our literature search did not locate enough relevant primary studies. For example, only 1 study quantified impacts of invasive mobile consumers on biodiversity of plants (Altieri et al. 2009) and none on sessile filter-feeders. Still, we expect that 'trophic downward' effects on biodiversity are also predictable (see Fig. 1 and Supplement 3 at www.int-res.com/articles/suppl/m495p039_supp.pdf). For example, invasive predators could have indirect positive effects on plant communities through cascading consumption (Schmitz et al. 2000, Dyer \& Letourneau 2003). Net effects of invasive omnivores may be more difficult to predict as they can have negative impacts on both plant and animal diversity through consumption and competition and may also provide food to higher trophic levels, as shown for invasive freshwater omnivores (Nyström \& Strand 1996, Perry et al. 1997, Parkos et al. 2003). Finally, the direction of the effect size may vary with environmental conditions, as invaders can compete with or facilitate communities within trophic/functional positions depending on abiotic stress levels (Bertness \& Callaway 1994).

The previous discussion on study limitations also outlines research gaps; many types of research bias should be reduced as studies accumulate, in particular if invasive species from under-represented trophic and functional groups are targeted. It is also important that more studies report biodiversity effects on finer trophic/functional groupings. For example, separating diversity impact for the local plant, filter-feeder, grazer, omnivore, and predator communities would be an important improvement. Future syntheses should also quantify biodiversity effects on lower trophic levels and pair positions of the invader and the local species with their size structures, ontogenies, strategies, densities, and interversus intra-trophic functional groupings (e.g. understory, canopy, and encrusting communities responding differently to invaders, Britton-Simmons 2004). Finally, experimental data need to be compared to survey data, to better understand how impact may depend on spatio-temporal scales, invasion history, and methodological artifacts.

In conclusion, we have shown that invaders, across studies, typically have negative effects on biodiversity within a trophic level but positive effects on biodiversity of higher trophic levels. These results confirm the importance of pairing attributes of the invader and the impacted local community to provide simple predictions about how biodiversity is affected by invaders (Ricciardi 2003, Thomsen et al. 2011a). Our broad predictions do not require detailed trait data about the invader or theories about (lack of) co- 
evolutionary history with local communities, but this information is important to add to gain deeper predictive insight into invasion impacts (Strayer et al. 2006, Ricciardi et al. 2013). We also note that too few studies existed to calculate effects for many combinations of invaders and community attributes. More studies are therefore needed so that high-resolution trophic/functional position models can be merged with models that pair different invader and community attributes.

Acknowledgements. We thank A. Altieri, M. A. Hixon, and D. J. Ross for providing additional data from their publications. T.W. was supported by a Future Fellows grant from the Australian Research Council. We acknowledge the continuing financial support of the New Zealand Ministry of Science and Innovation and the National Institute of Water and Atmospheric Research (contract C01X0501).

\section{LITERATURE CITED}

Albins MA, Hixon MA (2008) Invasive Indo-Pacific lionfish Pterois volitans reduce recruitment of Atlantic coral-reef fishes. Mar Ecol Prog Ser 367:233-238

Altieri AH, Trussell GC, Ewanchuck PJ, Bernatchez G, Bracken ME (2009) Consumers control diversity and functioning of a natural marine ecosystem. PLoS One 4: e5291

- Bertness MD, Callaway R (1994) Positive interactions in communities. Trends Ecol Evol 9:191-193

> Blum JC, Chang AL, Liljesthrom M, Schenk ME, Steinberg MK, Ruiz GM (2007) The non-native solitary ascidian Ciona intestinalis (L.) depresses species richness. J Exp Mar Biol Ecol 342:5-14

Borenstein M, Hedges LV, Higgins JPT, Rothstein HR (2009) Introduction to meta-analysis. John Wiley \& Sons, West Sussex

Britton-Simmons KH (2004) Direct and indirect effects of the introduced alga Sargassum muticum on benthic, subtidal communities of Washington State, USA. Mar Ecol Prog Ser 277:61-78

Bruno JF, Bertness MD (2001) Habitat modification and facilitation in benthic marine communities. In: Bertness MD, Gaines SD, Hay ME (eds) Marine community ecology. Sinauer Associates, Sunderland, MA, p 201-218

Bruno JF, Fridley JD, Bromberg K, Bertness MD (2005) Insights into biotic interactions from studies of species invasions. In: Sax DF, Gaines SD, Stachowicz JJ (eds) Species invasions: insights into ecology, evolution and biogeography. Sinauer, Sunderland, MA, p 13-40

Bulleri F, Balata D, Bertocci I, Tamburello L, Benedetti-Cecchi L (2010) The seaweed Caulerpa racemosa on Mediterranean rocky reefs: from passenger to driver of ecological change. Ecology 91:2205-2212

Byers JE (2009) Competition in marine invasions. In: Rilov G, Crooks JA (eds) Biological invasions in marine ecosystems - ecological, management, and geographic perspectives. Springer-Verlag, Heidelberg, p 245-260

> Byers J, Reichard S, Randall JM, Parker IM and others (2002) Directing research to reduce the impact of nonindigenous species. Conserv Biol 16:630-640
Crooks JA (2009) The role of exotic marine ecosystem engineers. In: Rilov G, Crooks JA (eds) Biological invasions in marine ecosystems - ecological, management, and geographic perspectives. Springer-Verlag, Heidelberg, p 287-304

Cucherousset J, Olden JD (2011) Ecological impacts of nonnative freshwater fishes. Fisheries 36:215-230

Diamond J, Case TJ (1986) Overview: introductions, extinctions, exterminations, and invasions. In: Diamond J, Case TJ (eds) Community ecology. Harper \& Row, New York, NY, p 65-79

> Dyer LA, Letourneau D (2003) Top-down and bottom-up diversity cascades in detrital vs. living food webs. Ecol Lett 6:60-68

> Eastwood MM, Donahue MJ, Fowler AE (2007) Reconstructing past biological invasions: niche shifts in response to invasive predators and competitors. Biol Invasions 9: 397-407

Englund G, Sarnelle O, Cooper SD (1999) The importance of data-selection criteria: meta-analysis of stream predation experiments. Ecology 80:1132-1141

> Fridley JD, Stachowicz JJ, Sax DF, Seabloom EW and others (2007) The invasion paradox: reconciling pattern and process in species invasions. Ecology 88:3-17

> Gaertner M, Den Breeyen AD, Hui C, Richardson DM (2009) Impacts of alien plant invasions on species richness in Mediterranean-type ecosystems: a meta-analysis. Prog Phys Geogr 33:319-338

Gribben PE, Byers J, Clements M, McKenzie LA, Steinberg PD, Wright JT (2009) Behavioural interactions between ecosystem engineers control community species richness. Ecol Lett 12:1127-1136

- Griffen BD, Byers JE (2009) Community impacts of two invasive crabs: the interactive roles of density, prey recruitment, and indirect effects. Biol Invasions 11:927-940

Grosholz ED, Ruiz G (2009) Multitrophic effects of invasion in marine and estuarine systems. In: Rilov $G$, Crooks JA (eds) Biological invasions in marine ecosystemsecological, management, and geographic perspectives. Springer-Verlag, Heidelberg, p 305-324

- Gurevitch J, Morrison JA, Hedges LV (2000) The interaction between competition and predation: a meta-analysis of field experiments. Am Nat 155:435-453

Hollebone AL, Hay ME (2008) An invasive crab alters interaction webs in a marine community. Biol Invasions 10: 347-358

Kaplan I, Halitschke R, Kessler A, Sardanelli S, Denno RF (2008) Constitutive and induced defences to herbivory in above- and belowground plant tissue. Ecology 89: 392-406

- Morales CL, Traveset A (2009) A meta-analysis of impacts of alien vs. native plants on pollinator visitation and reproductive success of co-occurring native plants. Ecol Lett 12:716-728

- Nyström P, Strand JA (1996) Grazing by a native and an exotic crayfish on aquatic macrophytes. Freshw Biol 36: 673-682

> Oduor AMO, Gomez JM, Strauss SY (2010) Exotic vertebrate and invertebrate herbivores differ in their impacts on native and exotic plants: a meta-analysis. Biol Invasions 12:407-419

> Parker IM, Simberloff D, Lonsdale WM, Goodell K and others (1999) Impact: toward a framework for understanding the ecological effects of invaders. Biol Invasions 1:3-19

> Parker JD, Burkepile DE, Hay ME (2006) Opposing effects of 
native and exotic herbivores on plant invasion. Science 311:1459-1461

Parkos JJ III, Santucci VJ Jr, Wahl DH (2003) Effects of adult common carp (Cyprinus carpio) on multiple trophic levels in shallow mesocosms. Can J Fish Aquat Sci 60: 182-192

Perry WL, Lodge DM, Lamberti GA (1997) Impact of crayfish predation on exotic zebra mussels and native invertebrates in a lake-outlet stream. Can J Fish Aquat Sci 54: 120-125

Piazzi L, Ceccherelli G (2006) Persistence of biological invasion effects: recovery of macroalgal assemblages after removal of Caulerpa racemosa var. cylindracea. Estuar Coast Shelf Sci 68:455-461

Piazzi L, Balata D, Ceccherelli G, Cinellia F (2005) Interactive effect of sedimentation and Caulerpa racemosa var. cylindracea invasion on macroalgal assemblages in the Mediterranean Sea. Estuar Coast Shelf Sci 64:467-474

Powell KI, Chase JM, Knight TM (2011) A synthesis of plant invasion effects on biodiversity across spatial scales. Am J Bot 98:539-548

Ricciardi A (2003) Predicting the impacts of an introduced species from its invasion history: an empirical approach to zebra mussel invasions. Freshw Biol 48:972-981

Ricciardi A, Atkinson SK (2004) Distinctiveness magnifies the impact of biological invaders in aquatic ecosystems. Ecol Lett 7:781-784

Ricciardi A, Hoopes MF, Marchetti M, Lockwood JL (2013) Progress toward understanding the ecological impacts of non-native species. Ecol Monogr 83:263-282

Rilov G (2009a) The integration of invasive species into marine ecosystems. In: Rilov G, Crooks JA (eds) Biological invasions in marine ecosystems - ecological, management, and geographic perspectives. Springer-Verlag, Heidelberg, p 214-244

Rilov G (2009b) Predator-prey interactions of marine invaders. In: Rilov G, Crooks JA (eds) Biological invasions in marine ecosystems - ecological, management, and geographic perspectives. Springer-Verlag, Heidelberg, p 261-285

Rodriguez LF (2006) Can invasive species facilitate native species? Evidence of how, when, and why these impacts occur. Biol Invasions 8:927-939

Rosenberg MS, Adams DC, Gurevitch J (2000) Metawin: statistical software for meta-analysis, Version 2. Sinauer Associates, Sunderland, MA

Rosenthal R (1979) The file drawer problem and tolerance for null results. Psychol Bull 86:638-641

Ross DJ, Keough MJ, Longmore AR, Knott NA (2007) Impacts of two introduced suspension feeders in Port Phillip Bay, Australia. Mar Ecol Prog Ser 340:41-53

Salo P, Korpimäki E, Banks P, Nordström M, Dickman CR (2007) Alien predators are more dangerous than native

Editorial responsibility: Richard Osman,

Edgewater, Maryland, USA predators to prey populations. Proc R Soc Lond B Biol Sci 274:1237-1243

Schaffelke B, Hewitt CL (2007) Impacts of introduced seaweeds. Bot Mar 50:397-417

Schmitz OJ, Hambäck PA, Beckerman AP (2000) Trophic cascades in terrestrial systems: a review of the effects of carnivore removals on plants. Am Nat 155:141-153

Sellheim K, Stachowicz JJ, Coates RC (2010) Effects of a nonnative habitat-forming species on mobile and sessile epifaunal communities. Mar Ecol Prog Ser 398:69-80

Sol D, Vila M, Kuhn I (2008) The comparative analysis of historical alien introductions. Biol Invasions 10:1119-1129

Strayer DL, Eviner VT, Jeschke JM, Pace ML (2006) Understanding the long-term effects of species invasions. Trends Ecol Evol 21:645-651

Thomsen MS (2010) Experimental evidence for positive effects of invasive seaweed on native invertebrates via habitat-formation in a seagrass bed. Aquat Invasions 5: 341-346

> Thomsen MS, Wernberg T, Tuya F, Silliman BR (2009) Evidence for impacts of non-indigenous macroalgae: a meta-analysis of experimental field studies. J Phycol 45: 812-819

> Thomsen MS, Wernberg T, Altieri A, Tuya F and others (2010) Habitat cascades: the conceptual context and global relevance of facilitation cascades via habitat formation and modification. Integr Comp Biol 50:158-175

> Thomsen MS, Olden JD, Wernberg T, Griffin JN, Silliman BR (2011a) A broad framework to organize and compare ecological invasion impacts. Environ Res 111: 899-908

Thomsen MS, Wernberg T, Olden JD, Griffin JN, Silliman BR (2011b) A framework to study the context-dependent impacts of marine invasions. J Exp Mar Biol Ecol 400: 322-327

Tronstad M, Hall RO, Koel TM, Gerow KG (2010) Introduced lake trout produced a four-level trophic cascade in Yellowstone Lake. Trans Am Fish Soc 139:1536-1550

Viejo RM (1997) The effects of colonization by Sargassum muticum on tidepool macroalgal assemblages. J Mar Biol Assoc UK 77:325-340

Vilà M, Espinar JL, Hejda M, Hulme PE and others (2011) Ecological impacts of invasive alien plants: a metaanalysis of their effects on species, communities and ecosystems. Ecol Lett 14:702-708

> Wahl M (1989) Marine epibiosis. I. Fouling and antifouling: some basic aspects. Mar Ecol Prog Ser 58:175-189

> Williams SL (2007) Introduced species in seagrass ecosystems: status and concerns. J Exp Mar Biol Ecol 350: 89-110

- Williams SL, Smith JE (2007) A global review of the distribution, taxonomy, and impacts of introduced seaweeds. Annu Rev Ecol Evol Syst 38:327-359

Submitted: December 6, 2012; Accepted: September 18, 2013 Proofs received from author(s): December 3, 2013 